\title{
Developing a Segmentation Model for Microscopic Images of Microplastics Isolated from Clams
}

Ho-min Park | 01-10-2021 | MAES Workshop @ ICPR

Ji Yeon Baek, Maria Krishna de Guzman, Ho-min Park, Sanghyeon Park, Boyeon Shin, Tanja Cirkovic Velickovic , Arnout Van Messem, and Wesley De Neve 


\section{MICROPLASTIC (MP) - CHARACTERIZATION}

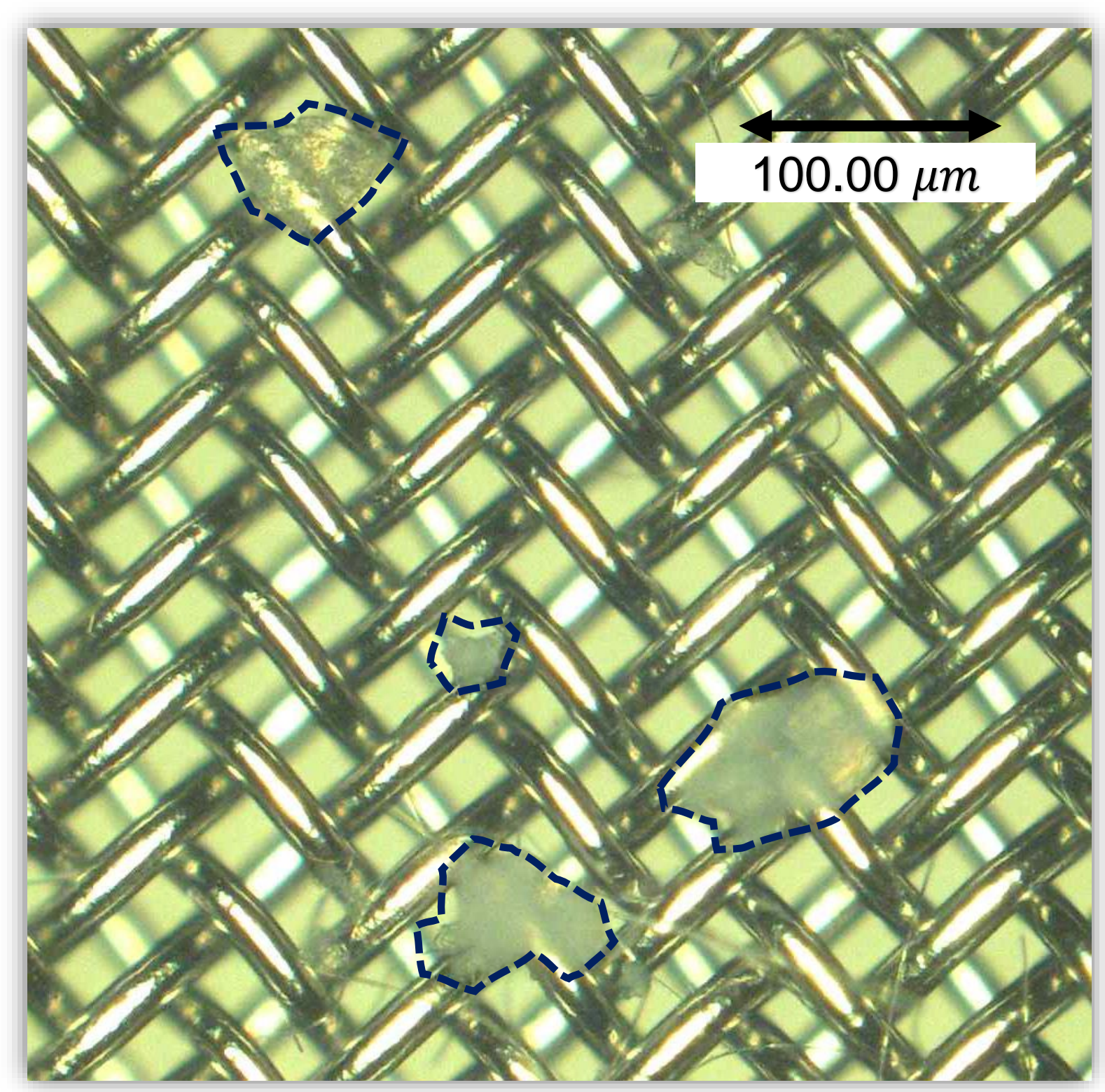

\begin{tabular}{|c|c|}
\hline Type & Size \\
\hline Macroplastic & $>5 \mathrm{~cm}$ \\
\hline Mesoplastic & $5 \mathrm{~cm}-5 \mathrm{~mm}$ \\
\hline Microplastic & $5 \mathrm{~mm}-0.1 \mu \mathrm{m}$ \\
\hline - Large MP & $5 \mathrm{~mm}-1 \mathrm{~mm}$ \\
\hline - Small MP & $1 \mathrm{~mm}-0.1 \mu \mathrm{m}$ \\
\hline Nanoplastic & $<0.1 \mu \mathrm{m}$ \\
\hline
\end{tabular}

\section{$\widehat{\underline{\underline{I I I I I}}}$}

GHENT UNIVERSITY GLOBAL CAMPUS
J. Li et al., "Using mussel as a global bioindicator of coastal microplastic pollution," Environ. Pollut., vol. 244, pp. 522-533, 2019. Arthur, C., Baker, J. \& Bamford, H. Proceedings of the International Research Workshop on the Occurrence, Effects, and Fate of Microplastic Marine Debris. Sept 9-11, 2008. 530 (2009) 


\section{MICROPLASTIC CONCENTRATION IN FOOD}

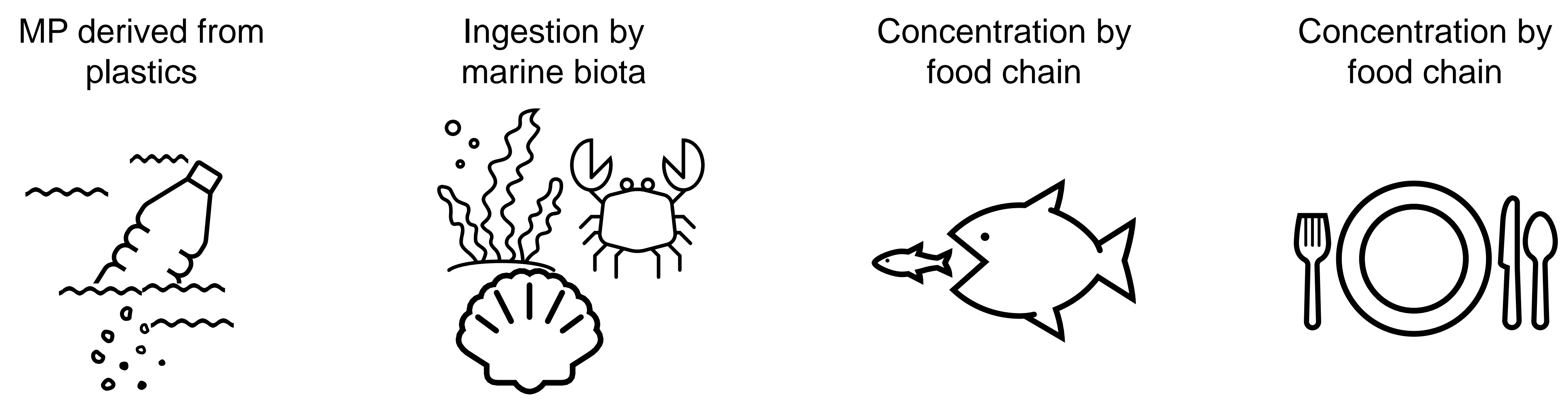

MP monitoring via Manila clams

Needs 8 phases 
WET LAB PHASE (PHASE 1 - 4)
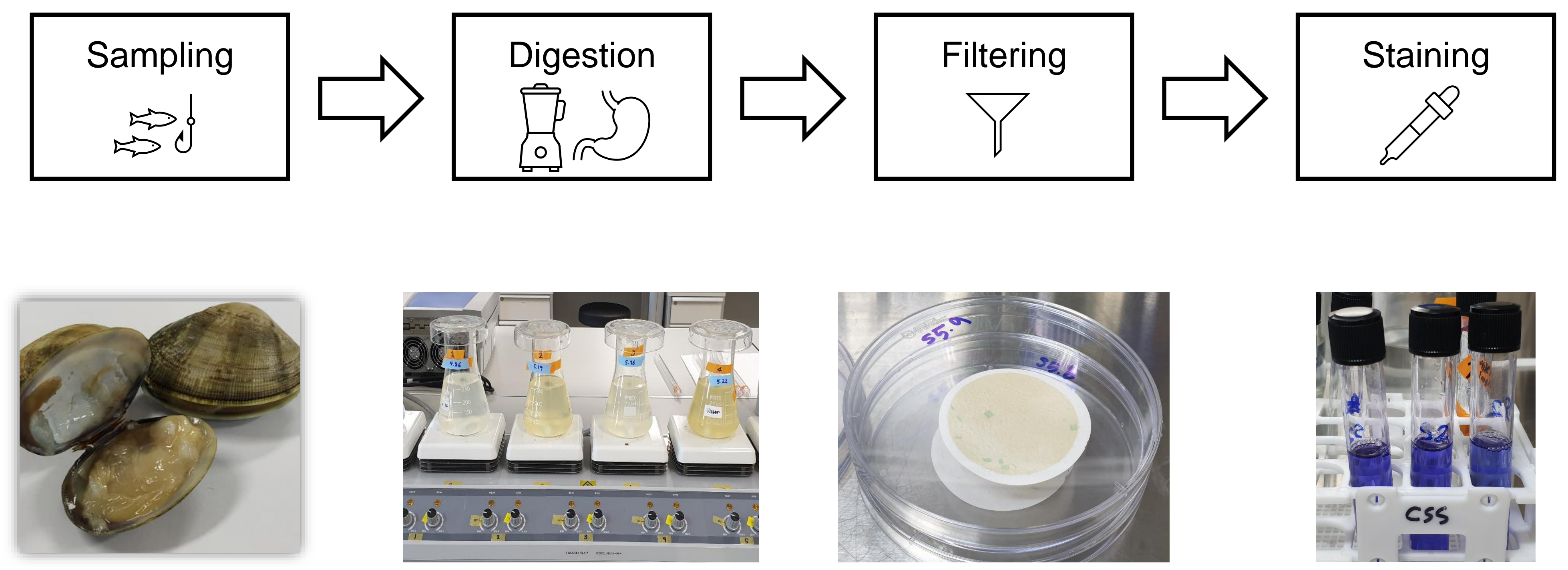

$\widehat{\underline{\text { IIIIII }}}$

GHENT UNIVERSITY

GLOBAL CAMPUS 


\section{DRY LAB PHASE (PHASE 5 - 8)}

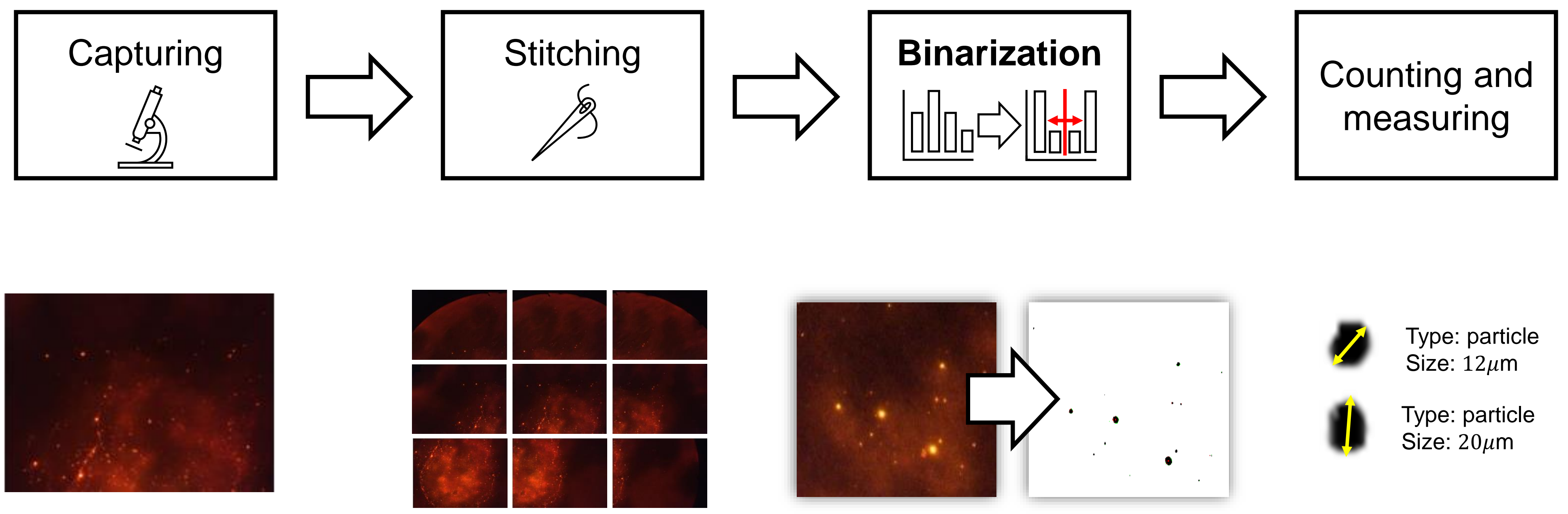




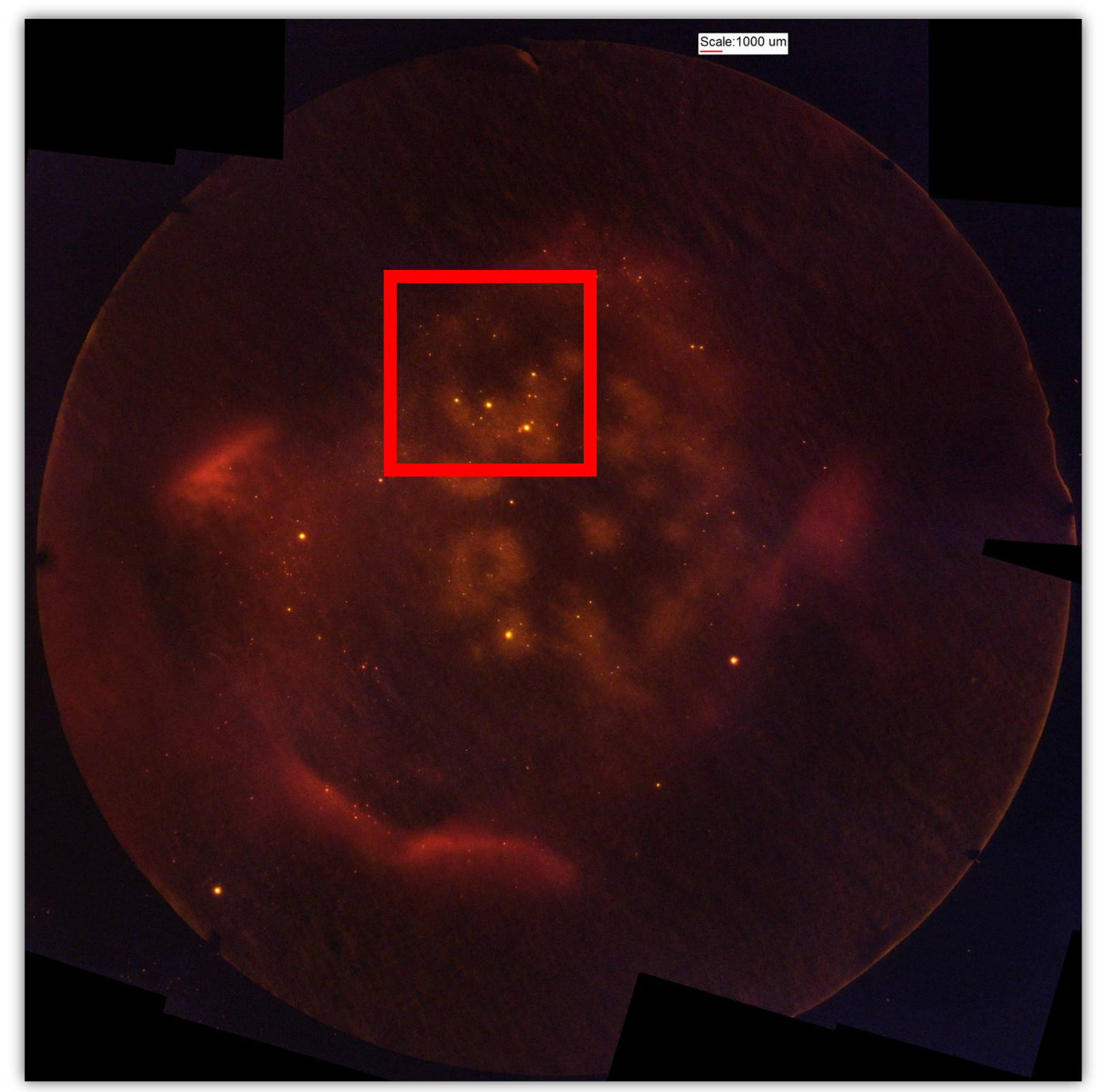

P6: High-resolution fluorescent image (stitched together)

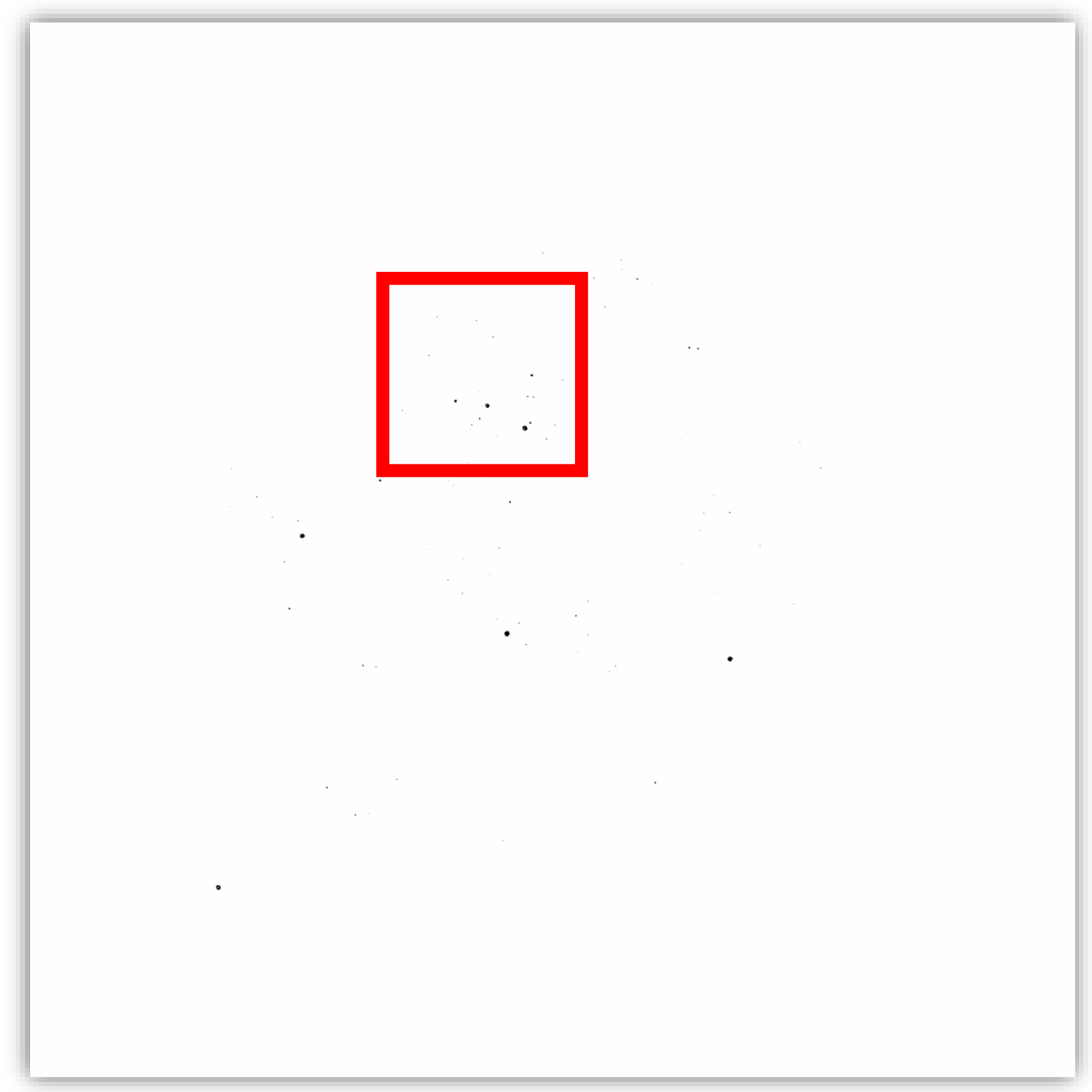

P7: Binarized image

(ground truth mask) 


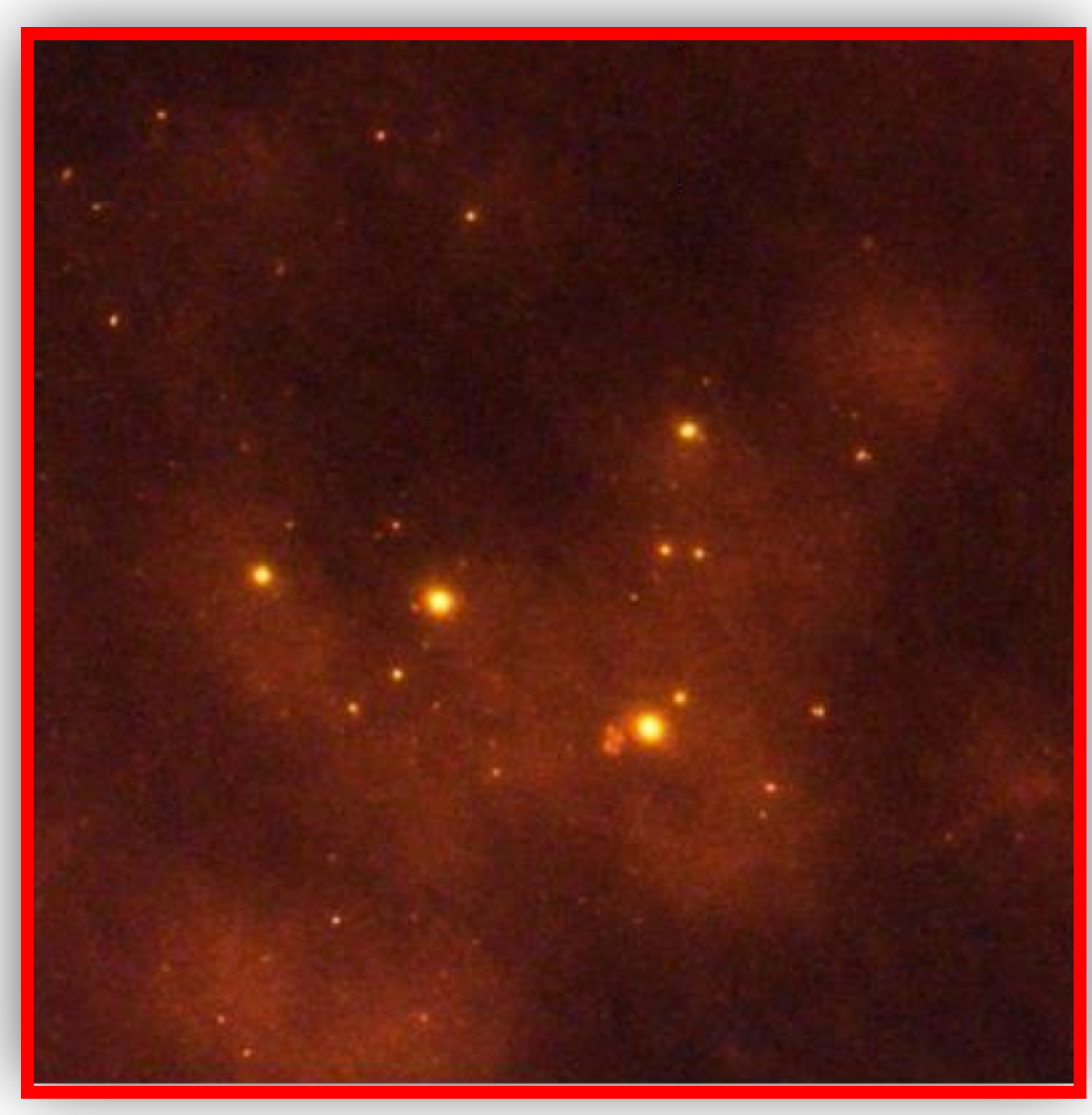

Magnified image

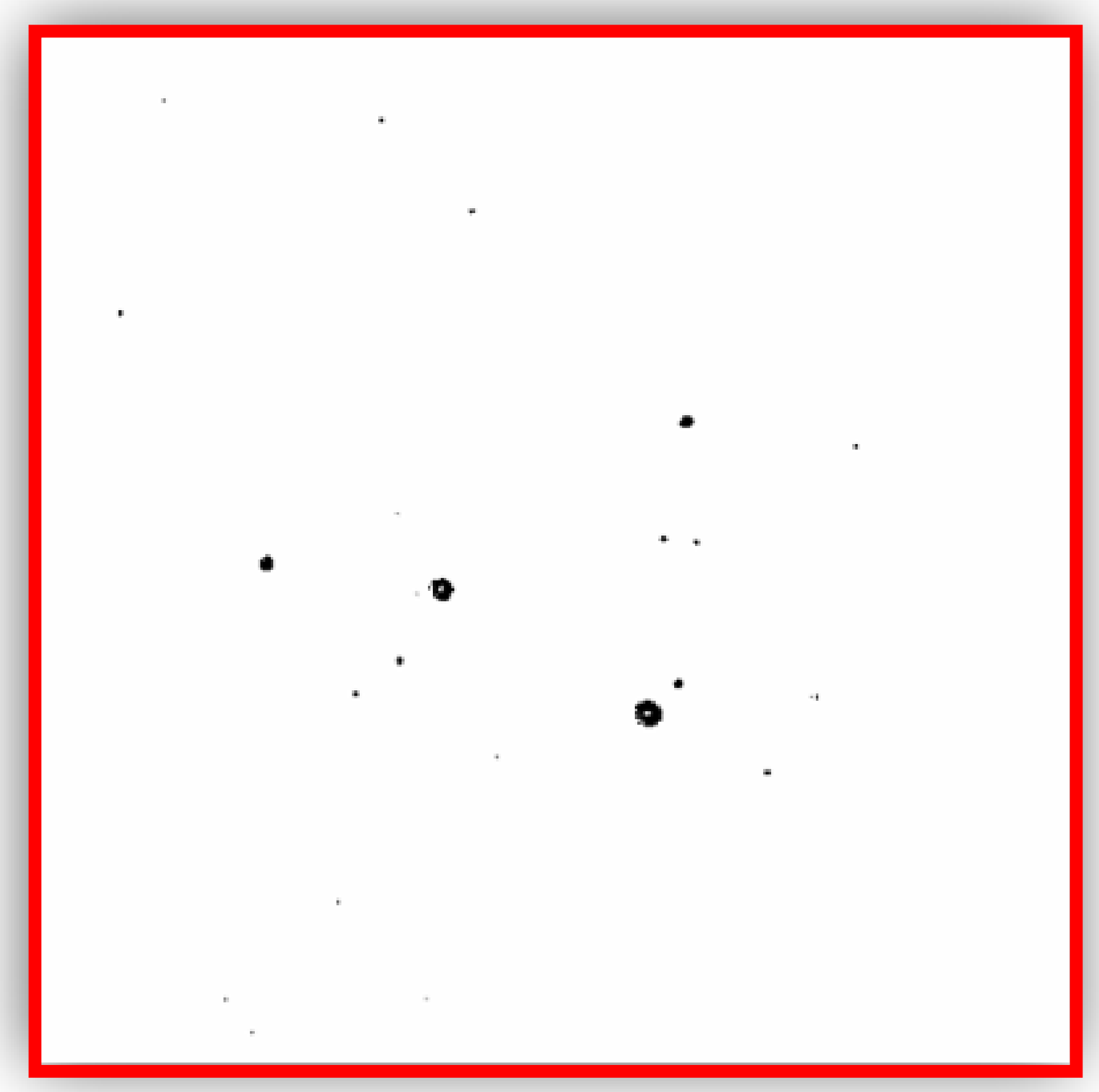

Ground truth 


\section{DRY LAB PHASE}
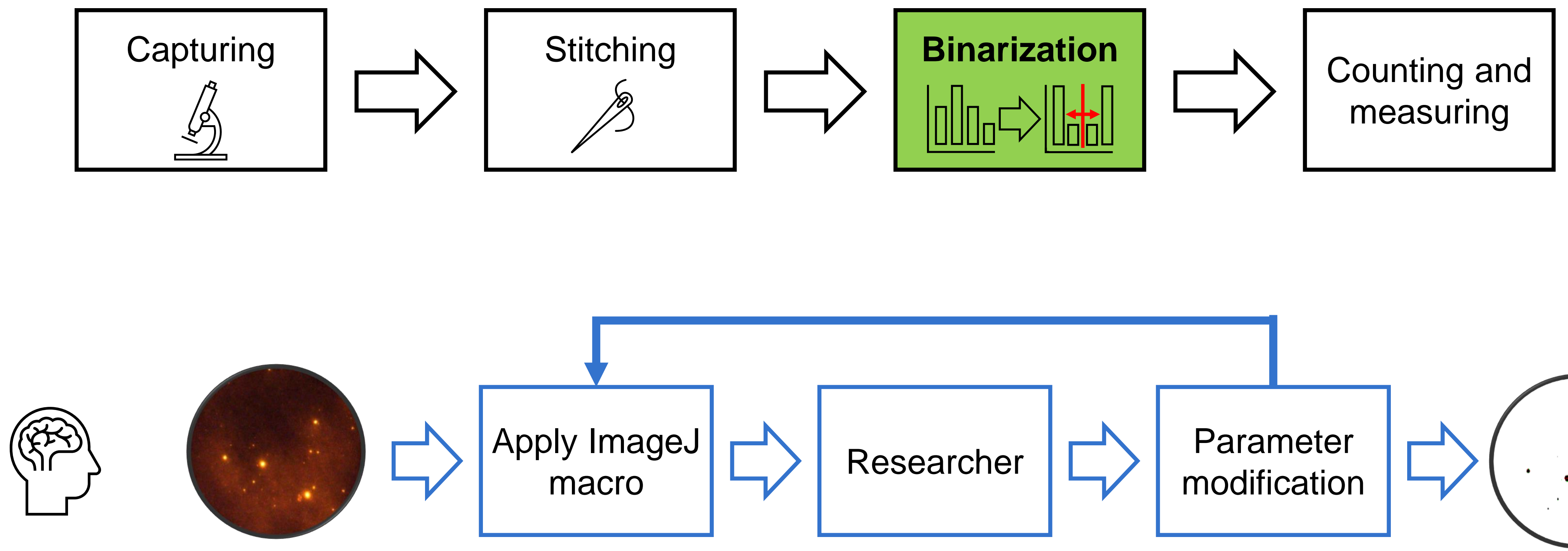

Original image

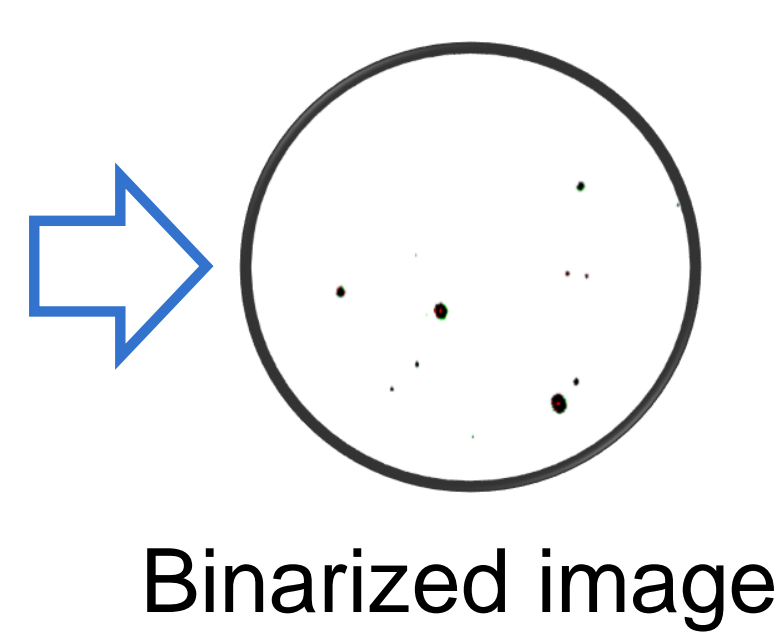

제III 


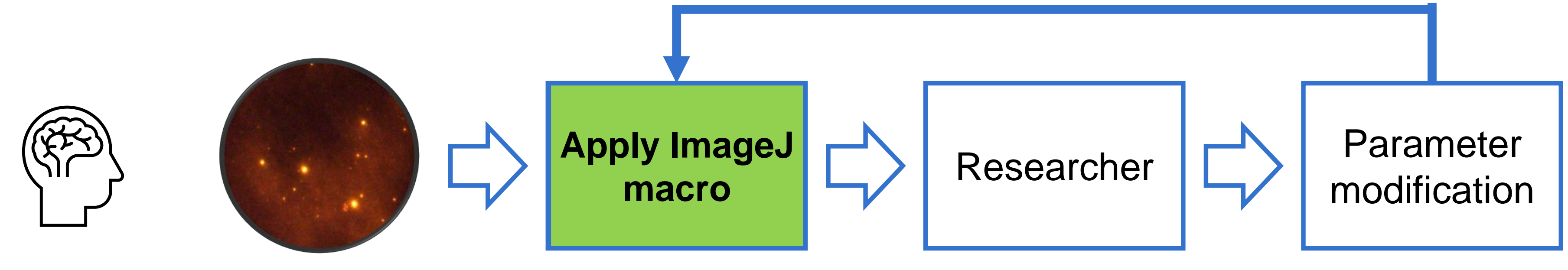

Original image

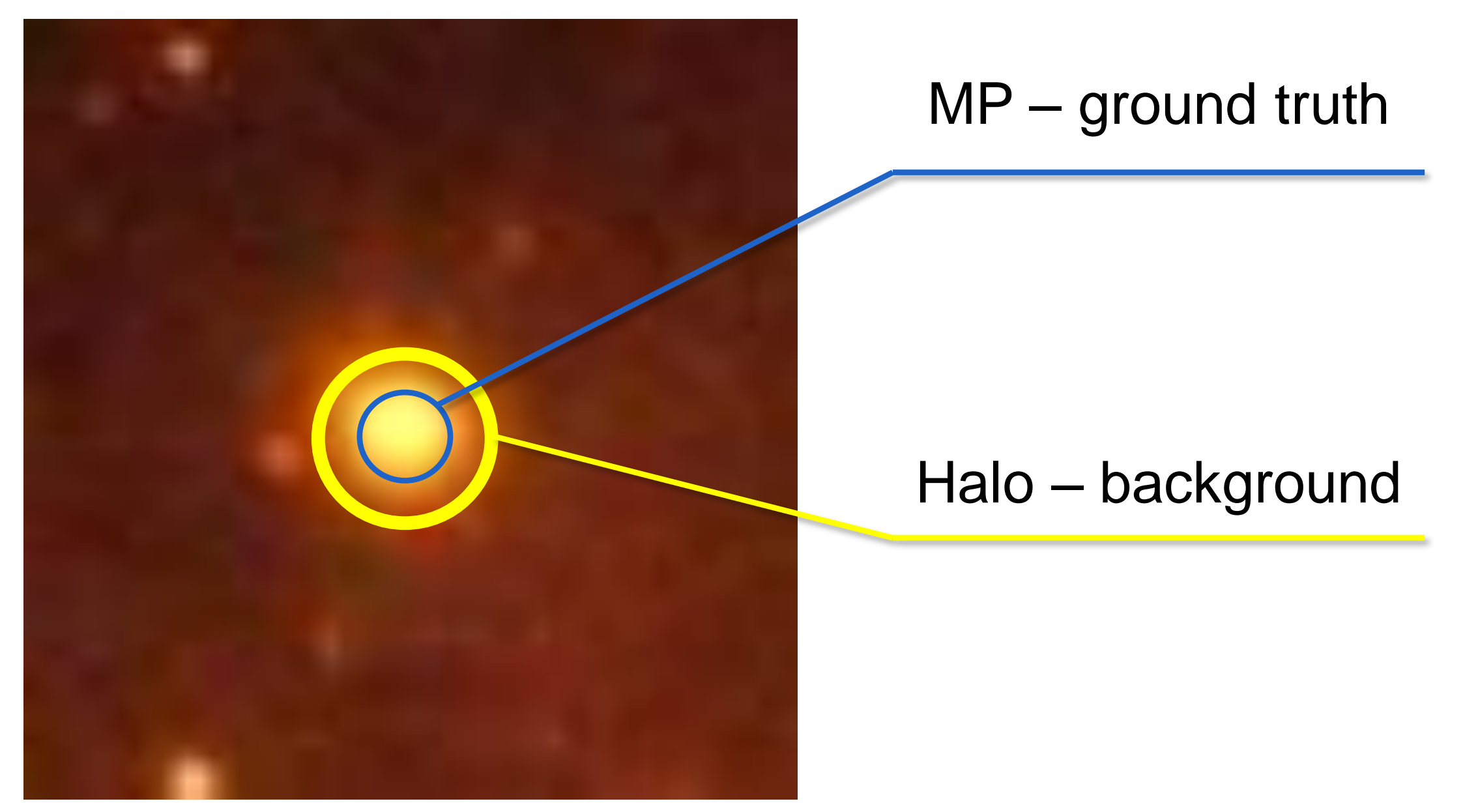

D Ground truth

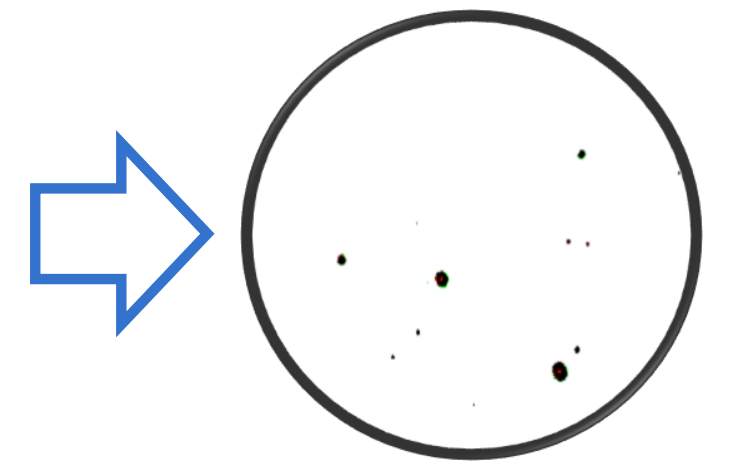

Binarized image

MP-VAT (overestimated) 


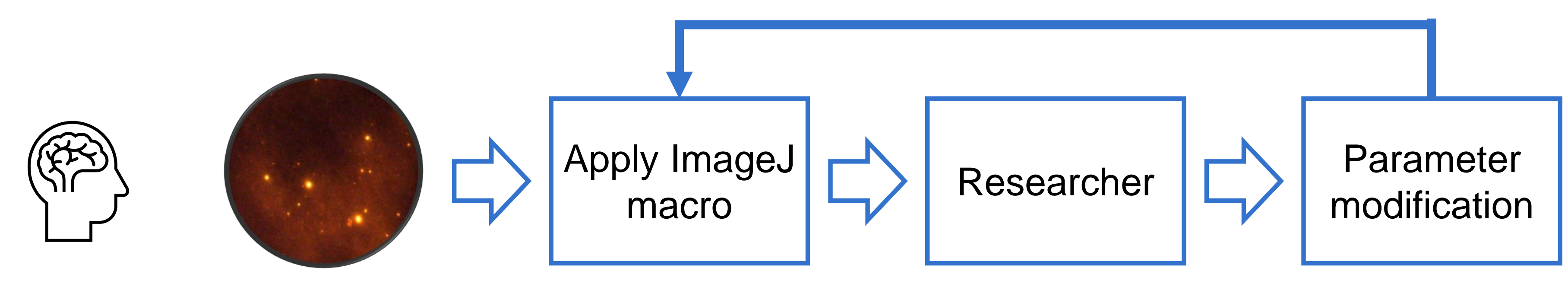

Original image

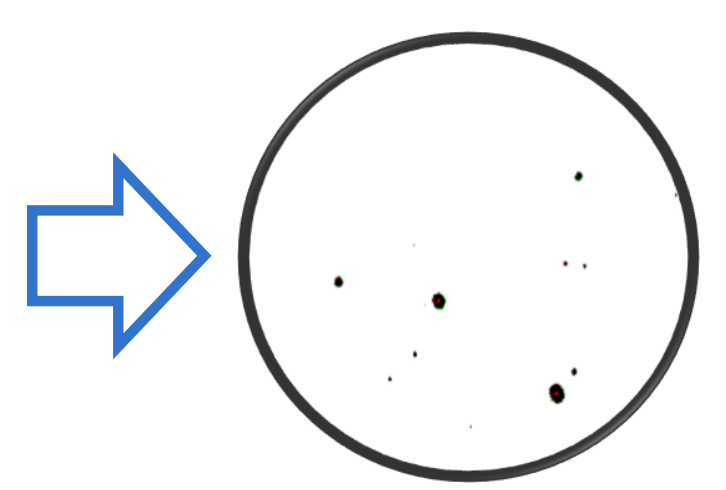

Binarized image

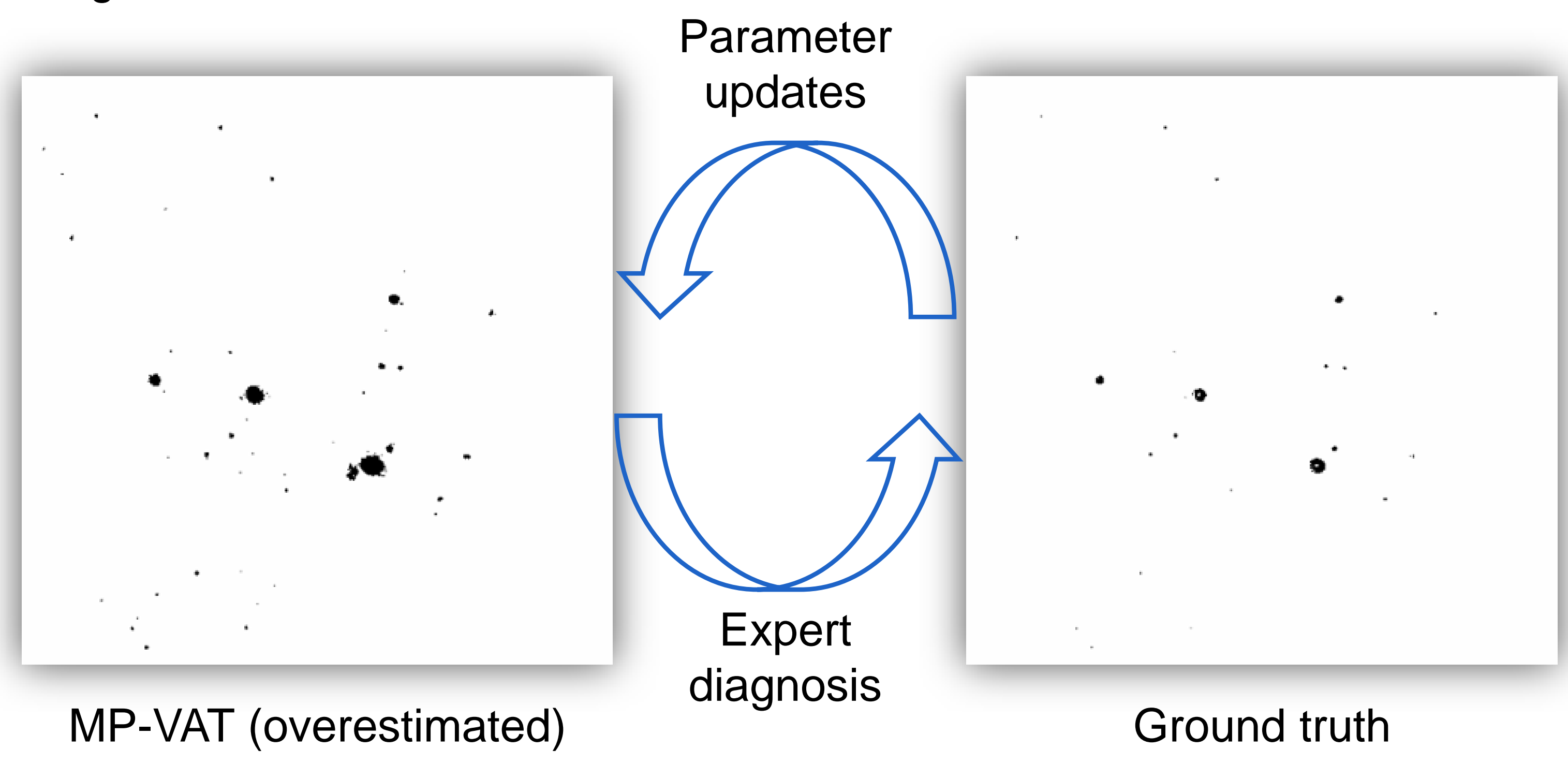




\section{DEEP SEGMENTATION MODEL}

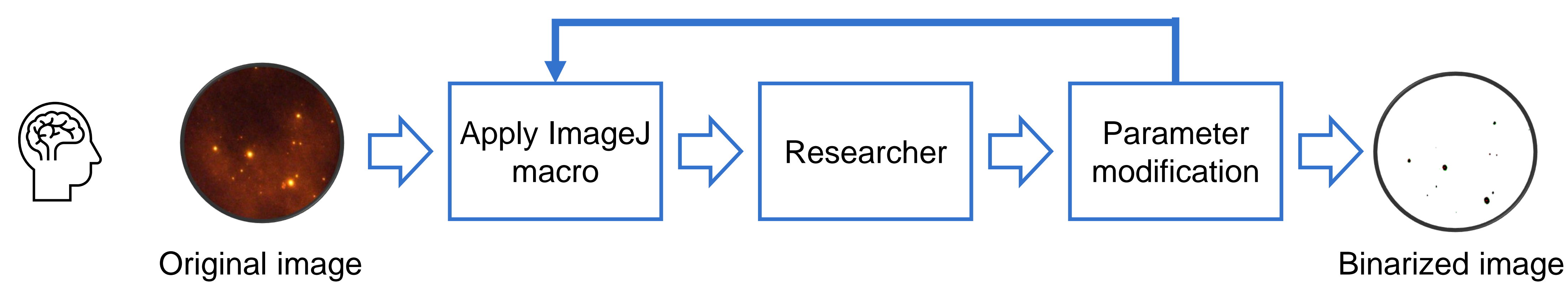

Original image

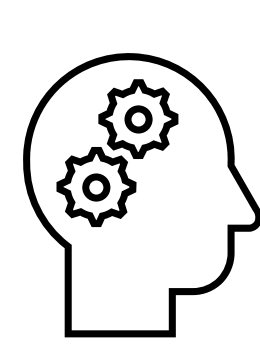

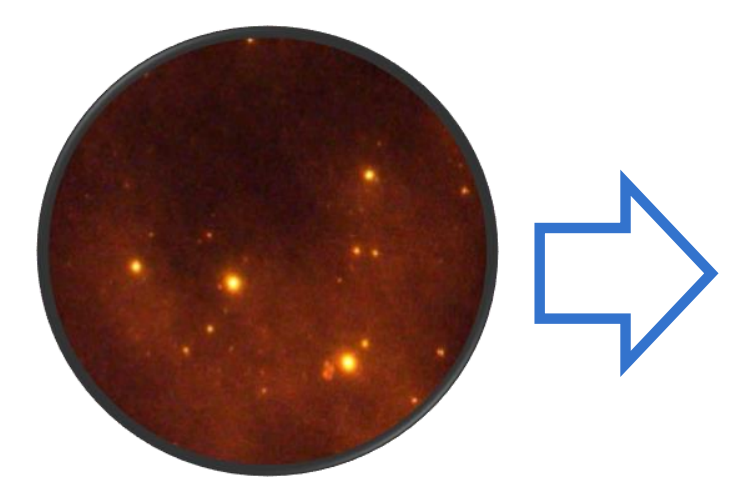

Original image
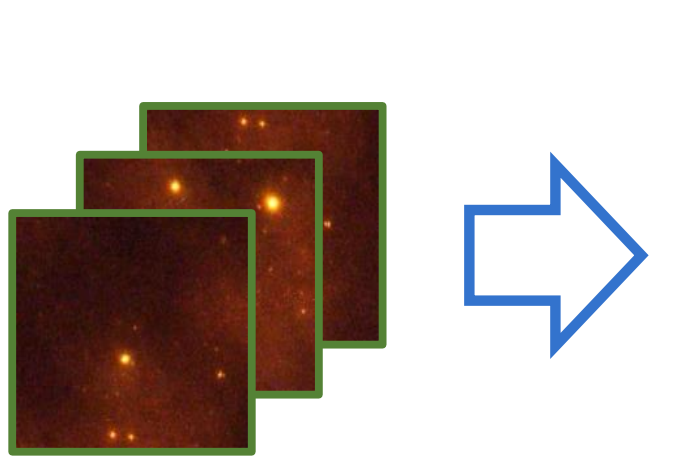

\section{Deep segmentation model}

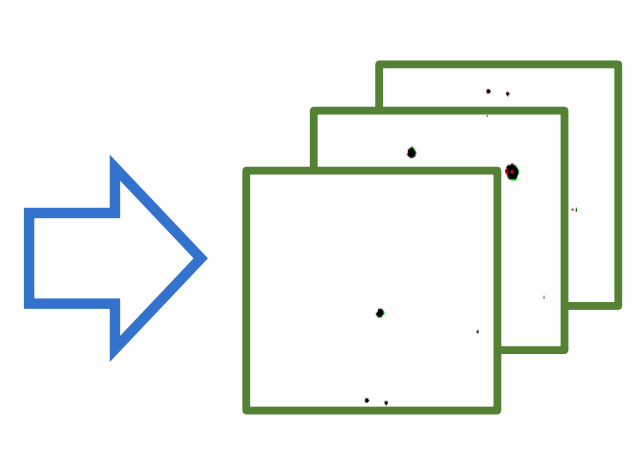

$\widehat{\underline{\underline{I I I I I}}}$

GHENT UNIVERSITY

GLOBAL CAMPUS

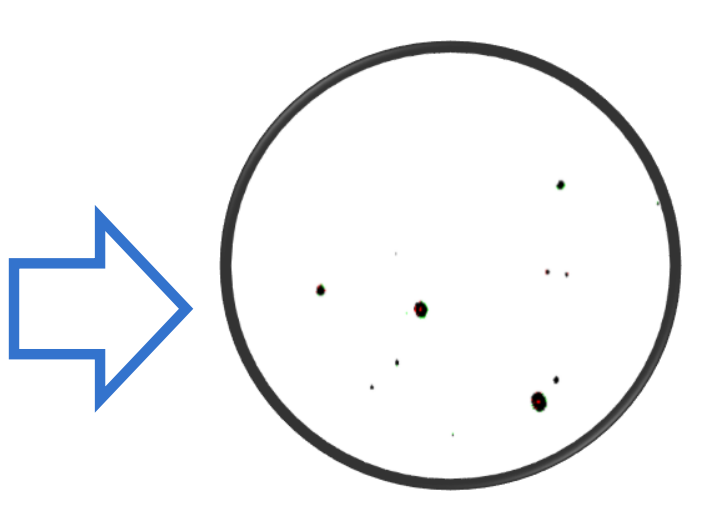

Binarized image 


\section{DATASET}

- 99 fluorescent microscopy images and corresponding masks

- resolution: $1280 \times 960-7140 \times 5424$

- Use of a sliding window, cropping, and random selection to generate 100,000 patches with a resolution of $256 \times 256$

- organized into 5 datasets of 20,000 patches

- 4 datasets for 4-fold cross-validation

- 1 dataset for testing 


\section{DEEP SEGMENTATION MODEL}

- Use of U-Net (pre-trained on ImageNet)

- initially developed for biomedical image segmentation

- now often used in other domains
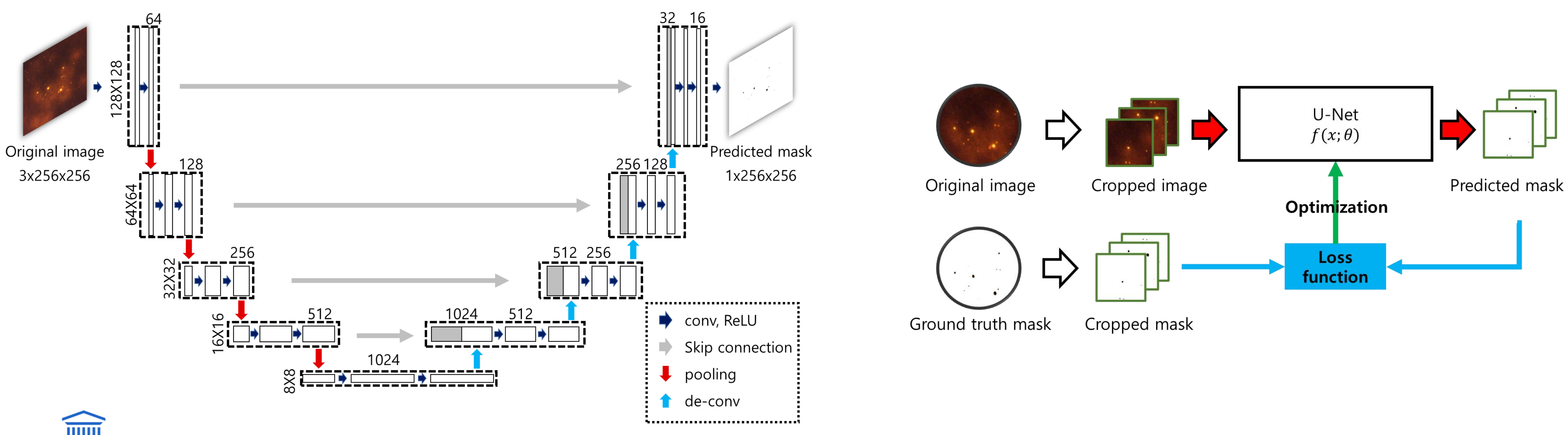


\section{QUANTITATIVE RESULTS}

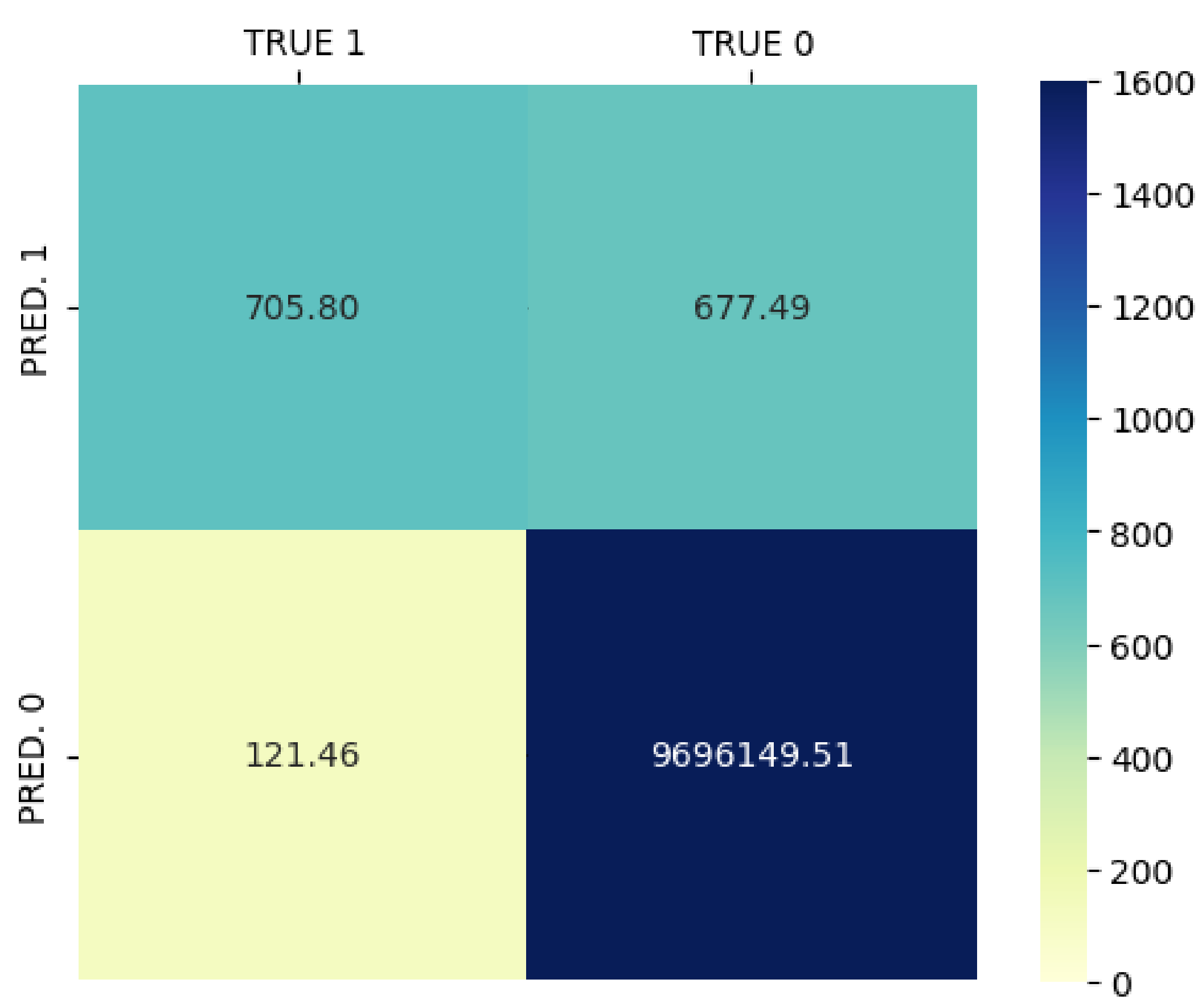

TP: \# of true positives $\mathrm{TN}$ : \# of true negatives FP: \# of false positives FN: \# of false negatives

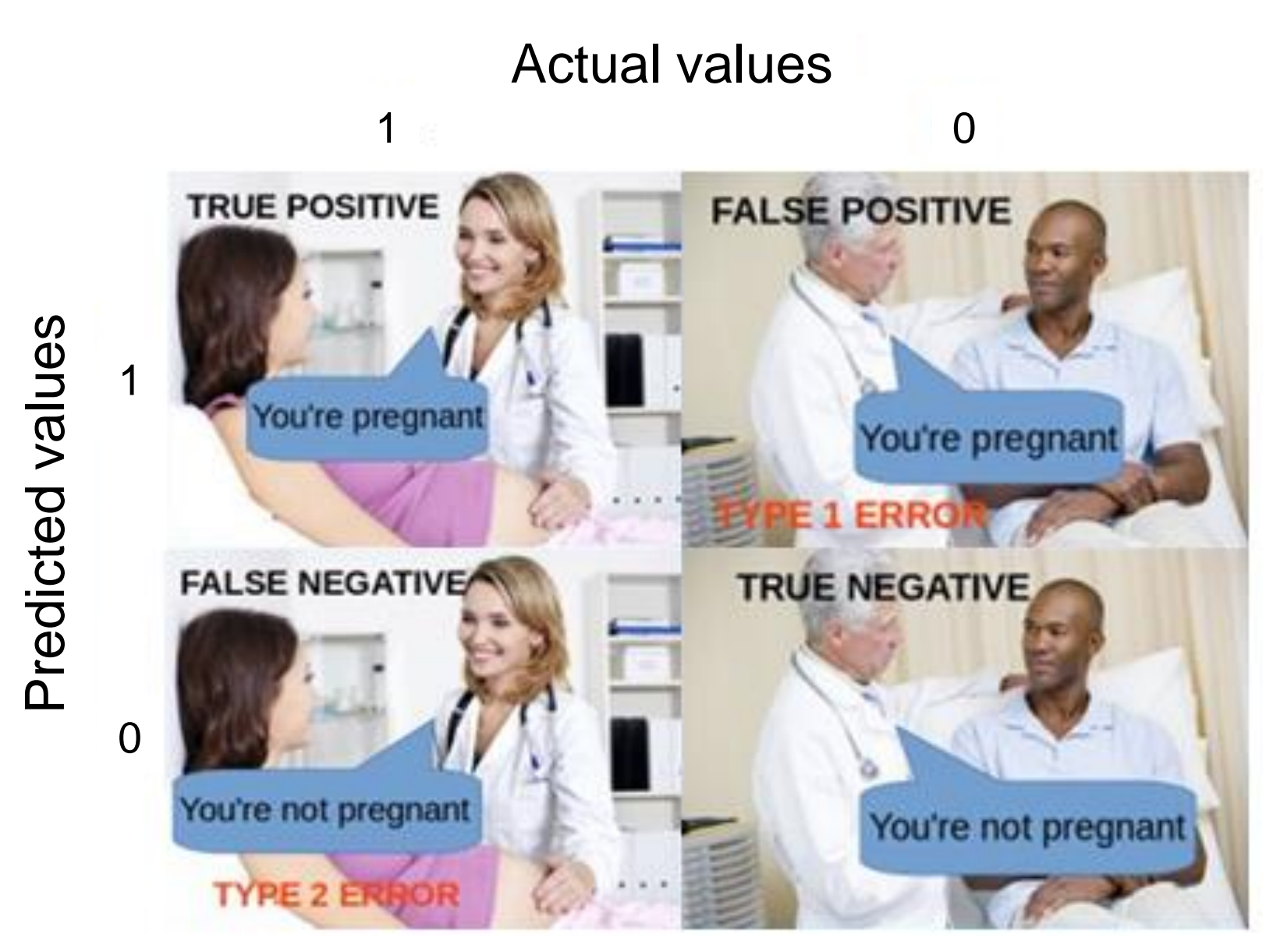

$\widehat{\underline{\underline{I I I I I}}}$

GHENT UNIVERSITY 


\section{QUANTITATIVE RESULTS}
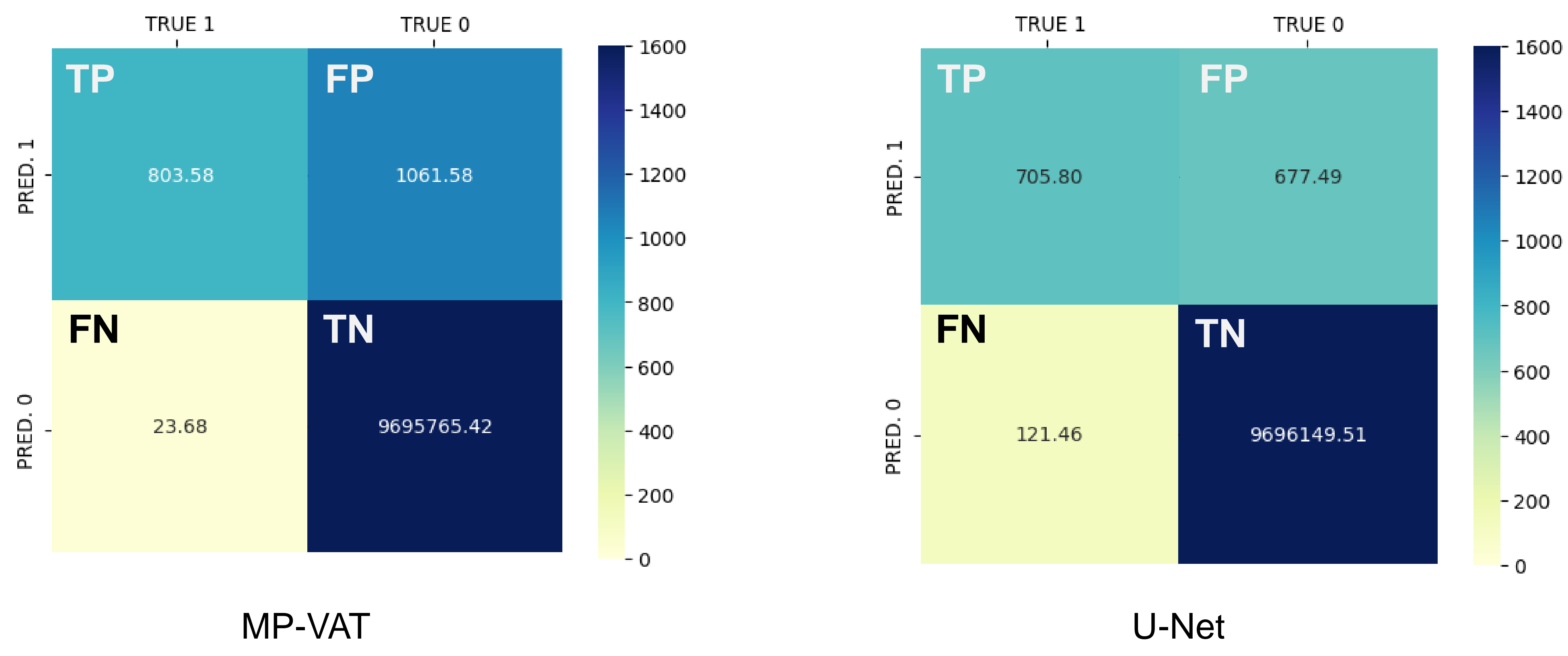

(1) high number of true negatives (background pixels can be predicted well) (2) reduced number of false positives 


\section{QUALITATIVE RESULTS (HALO DETECTION)}

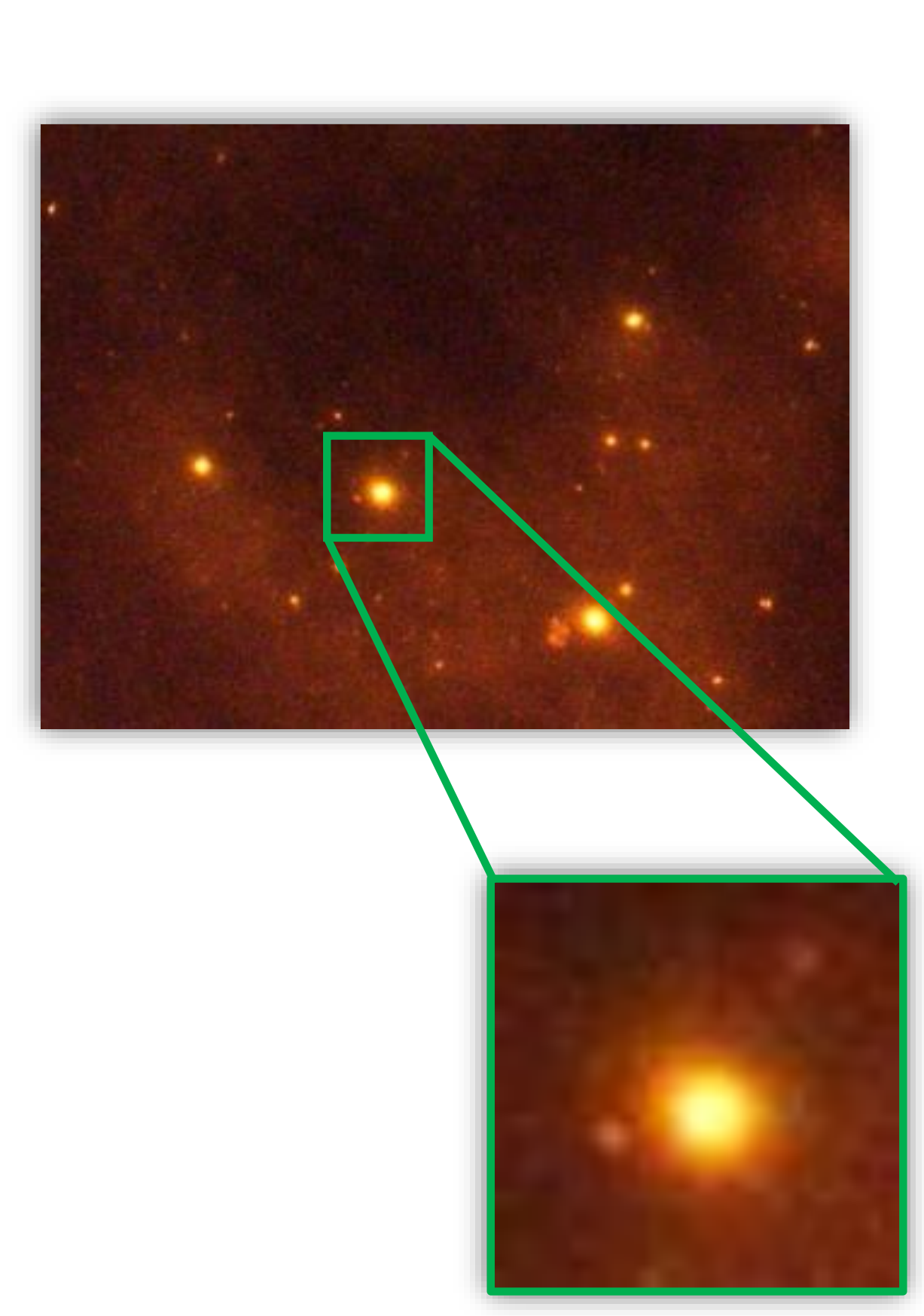

$\widehat{\underline{\mathrm{IIIIIII}}}$

GHENT UNIVERSITY

GLOBAL CAMPUS

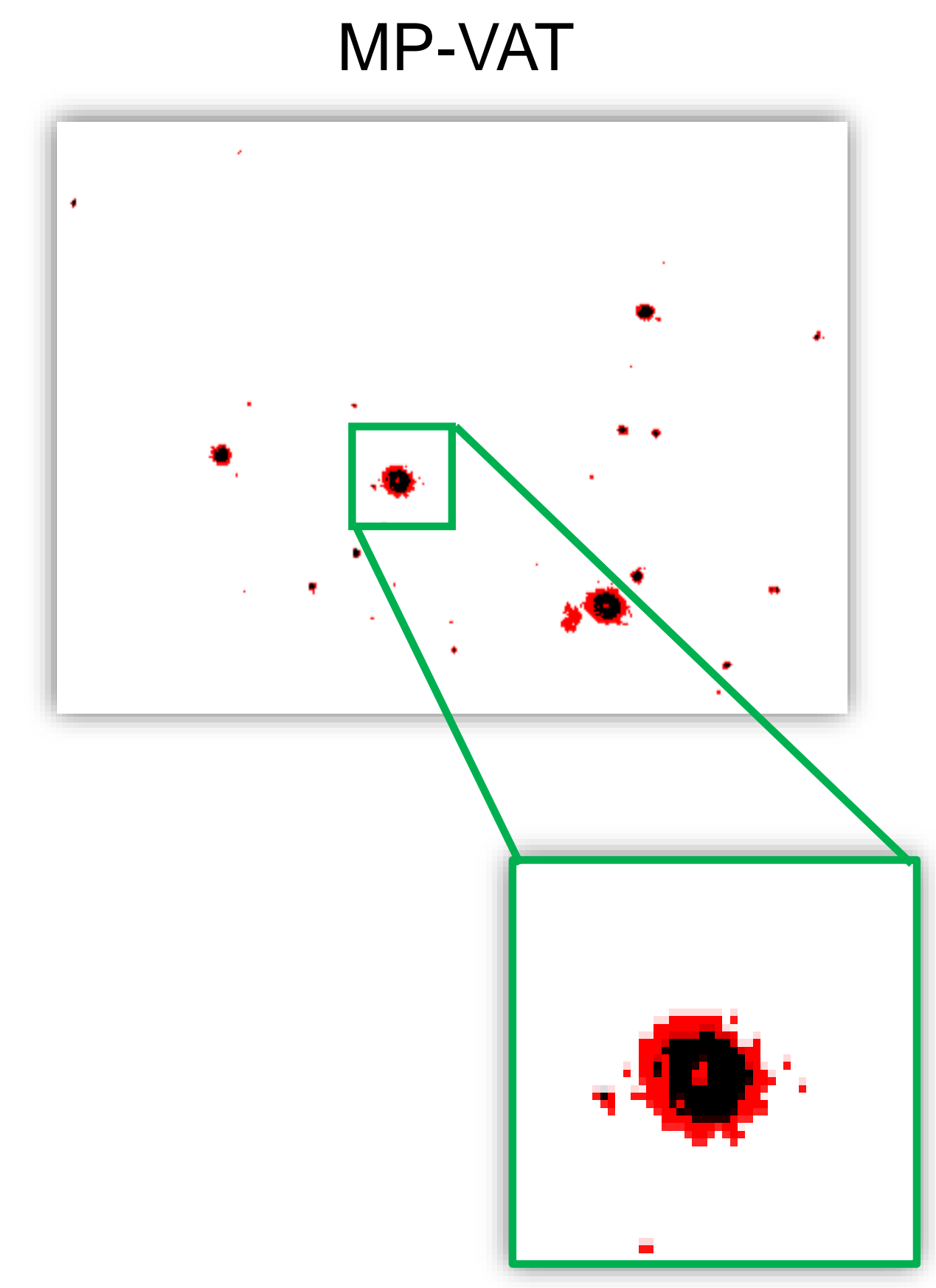

white and black pixels: correctly predicted red pixels: false positives green pixels: false negatives 


\section{QUALITATIVE RESULTS (NOISE REMOVAL)}
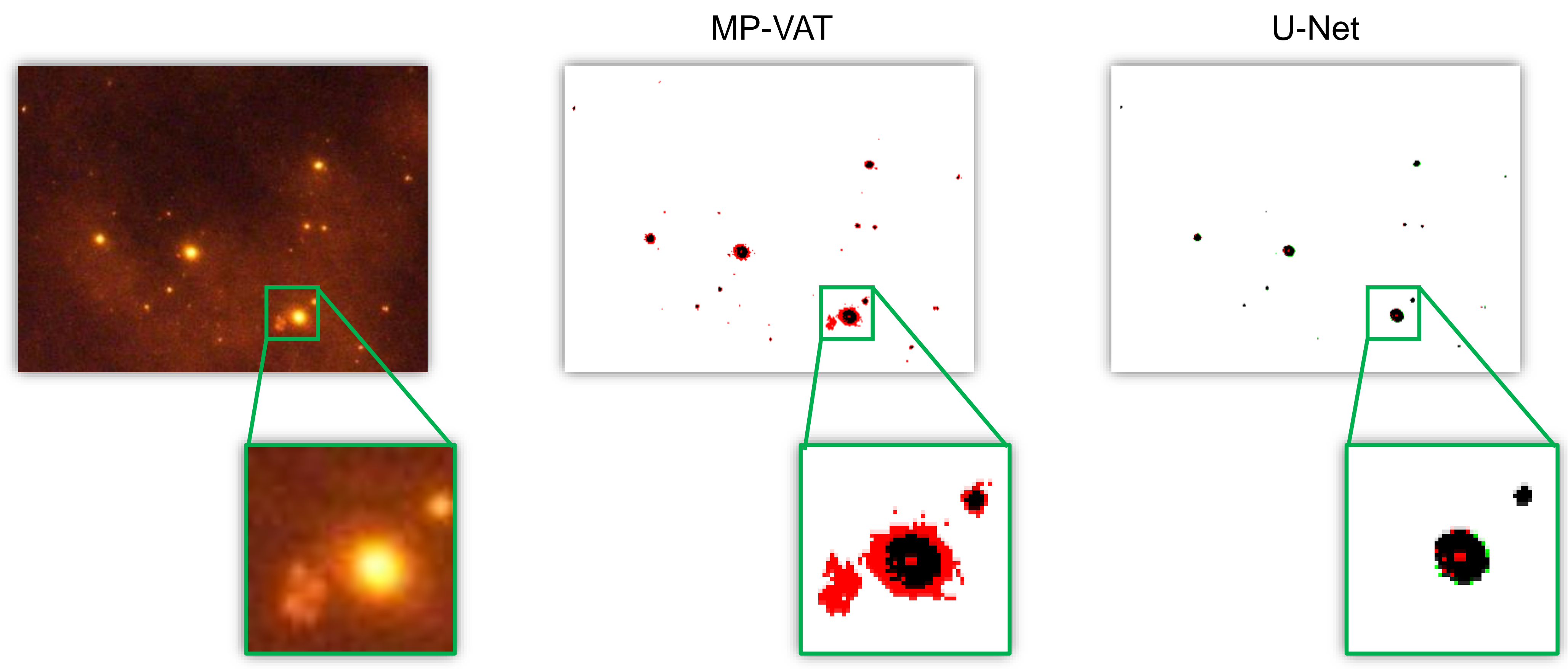

$\widehat{\underline{\underline{I I I I I I}}}$

white and black pixels: correctly predicted red pixels: false positives 


\section{QUALITATIVE RESULTS (LOSS FUNCTIONS)}

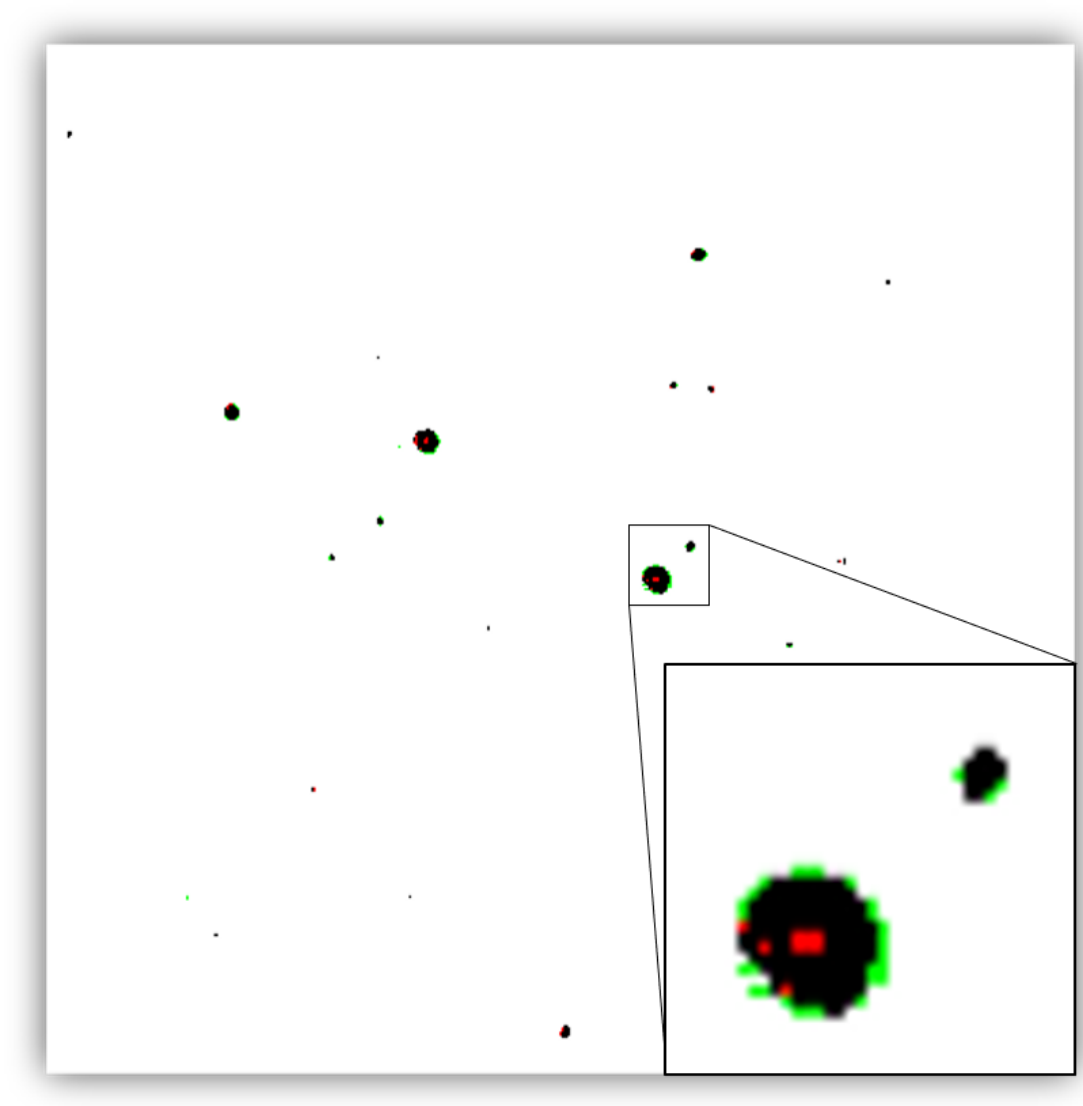

U-Net (1)

BCE with logits loss and SGD

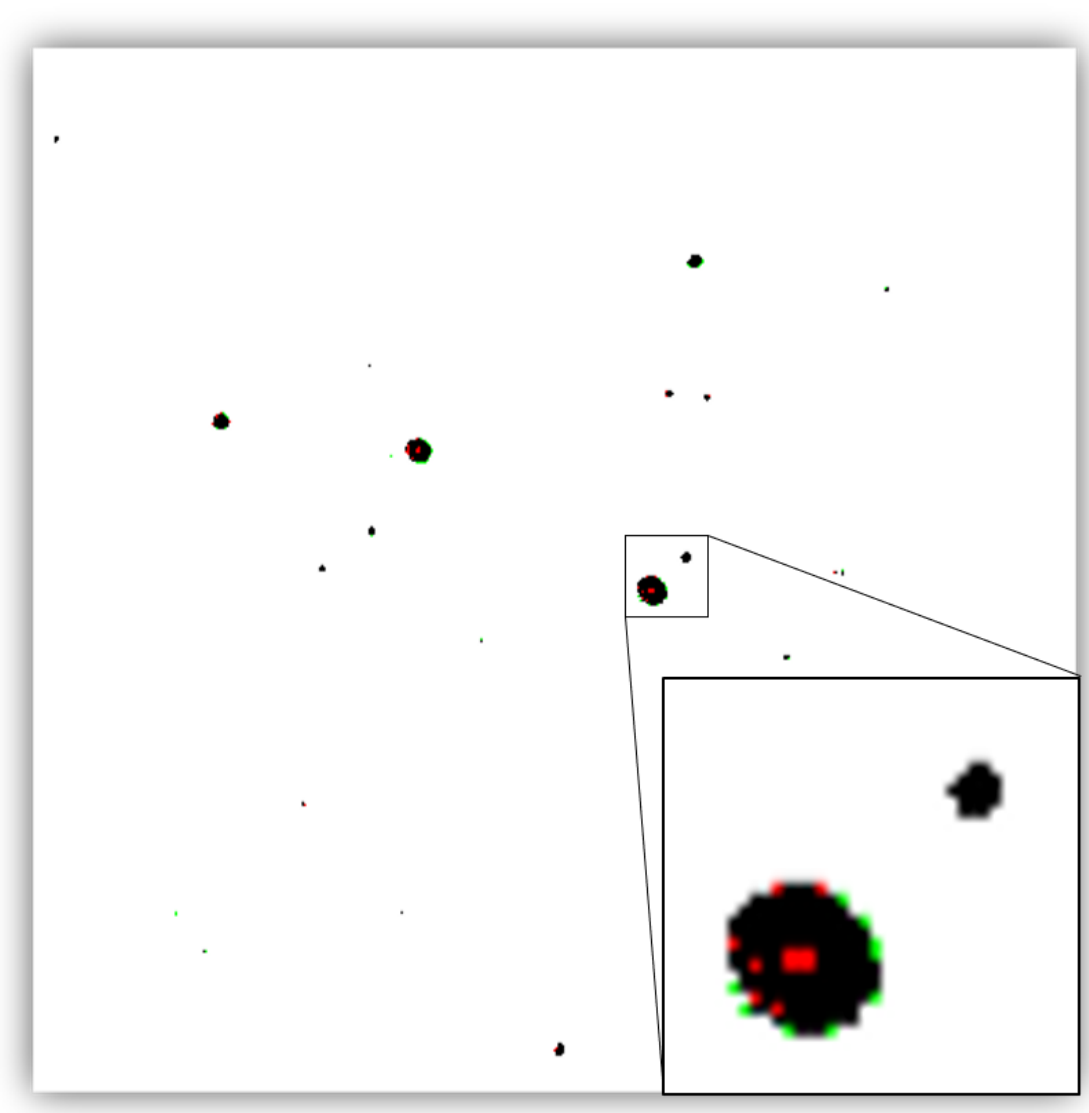

U-Net (2)

Dice loss and Adam

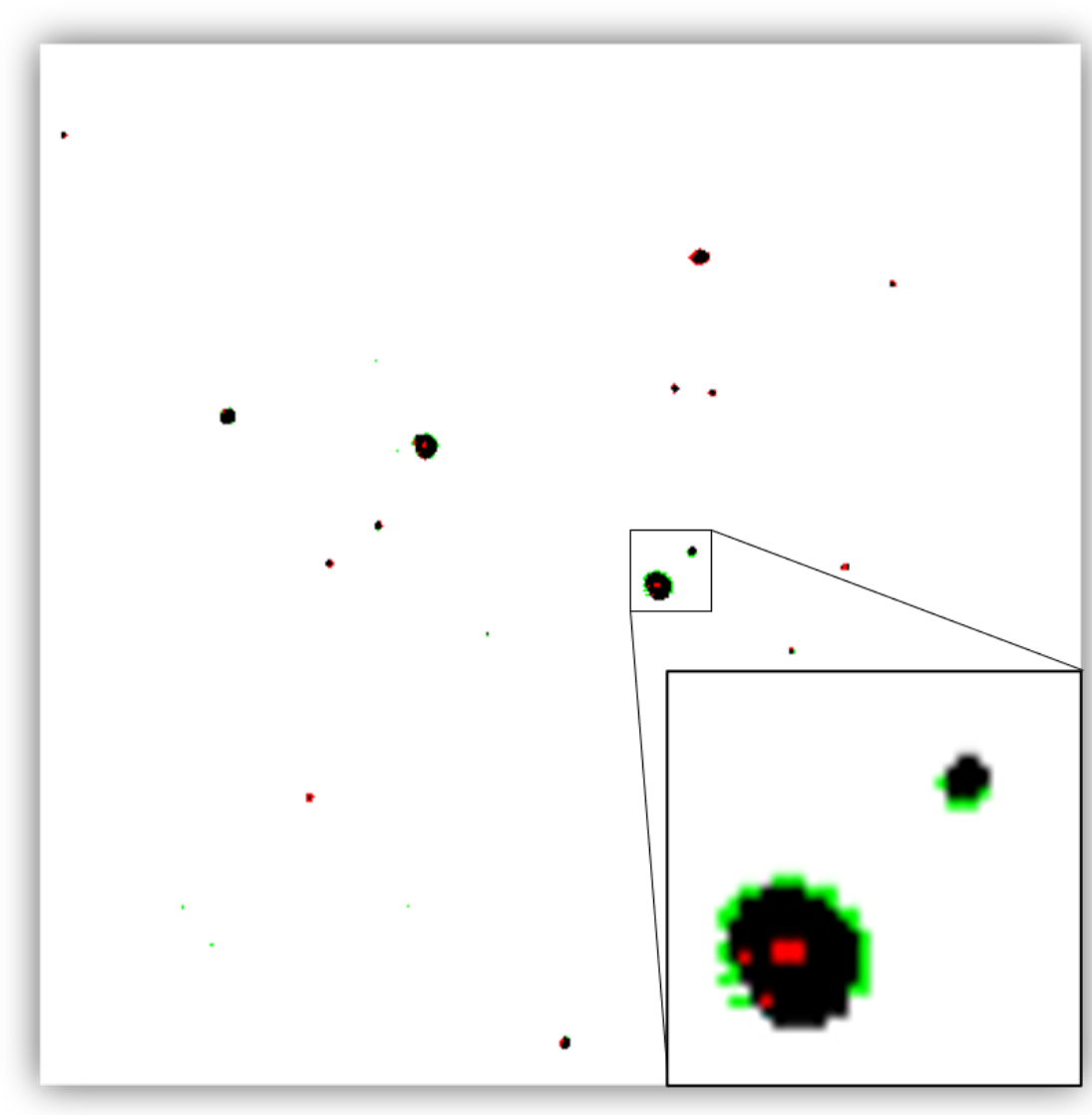

U-Net (3)

BCE with dice loss and Adam 


\section{SUMMARY}

- MP monitoring using marine biota (i.e., Manila clams)

- MP detection in microscopic images

- MP-VAT (manual intervention, prone to errors)

- U-Net (deep learning, highly automated)

- Better results in terms of false positive detection $\left(\mathrm{F}_{0.5}\right.$, precision)

- Alternative to already existing methods 


\section{FUTURE WORK}

- Model improvement

- reduction of false positives

- comparison to other segmentation models

- optimization of hyperparameter values (vs. default ones)

- Better accessibility \& usefulness

- GUI interface or ImageJ macro

- integration of support for counting and finding size and shape 


\section{Thank you for your attention! Any questions?}

Ho-min Park

E homin.park@ghent.ac.kr

M +82 326264326 